SEX ETHICS : The Principles and Practice of Contraception, Abortion and Sterilization.

By JoHN El.lison, B.A., M.B., B.Ch. (Cantab.), F.R.C.S. (Ed.), F.C.O.G.

Aubrey Goodwin, O.B.E., M.D., B.S. (Lond.), F.R.C.S. (Eng.), F.R.C.S. (Ed.).

Charles D. Read, M.B., Ch.B. (N. Z.), F.R.C.S. (Ed.), F.R.A.C.S., M.C.O.G.

L. Carnac RivetT, M.A., M.C. (Cantab.), F.R.C.S. (Eng.), M.C.O.G.

London: Ballière, Tindall and Cox. 1934. Price, 12/6.

So much suggestive and prurient writing has appeared in connection with these great problems of contraception, abontion and sterilization that it is a pleasure to welcome an authoritative medical statement on these matters by well-known teachers of obstetrics and gynæcology. Incorporated in this book are religious and legal opinions, all of them highly controversial. Even the medical opinions, in some instances, are contrary to the highest standards. For example, on page 21 , it is stated that "the desire of a single woman to have not merely her sexual desires but her maternal instincts satisfied must be considered." This is quite unethical, just as is the suggestion that there should be laws controlling, not prohibiting prostitution. The reviewer would differ from the authors in whole-heartedly condemning the practice of contraception in the unmarried and in the married who adopt it as a safeguard in illicit relations : what ought to be urged in these days is a greater sense of moral responsibility, otherwise there will soon be little to differentiate the human race from the beasts of the field.

Abortion and sterilization are considered from all aspects. In connection with the former, attention is rightly drawn to the nefarious trade in abortifacients, and to the fact that it is apparently not illegal to advertise such remedies as purporting to cure "female irregularities."

Probably enough has been said to indicate that the book is a very valuable collection of opinions-medical, religious and legal. The information is conveyed in a clear and interesting manner, the type is good, and there are 21 useful plates. The book ought to be read by every medical man so that his own ideas on these matters may be crystallised in response to the challenge of those advanced by the authors.

\section{ILLUSTRATIONS OF REGIONAL ANATOMY.}

By E. B. JAmieson, M.D. In five sections : I, Central Nervous System, 7/-; II, Head \& Neck, 10/-; III, Abdomen, 5/6; IV, Pelvis, 3/6; V, Thorax; 4/-. Price complete 30/- net. Edinburgh, E. \& S. Livingstone, 1934.

This work consists of 258 illustrations on 203 separate plates mounted in five regional groups in stout folders on the "peg" loose-leaf principle. The plates can be rearranged, or any one readily removed for pasting into a notebook or for demonstration in an epidiascope. The illustrations are clearly drawn pictures of dissections or sections, usually somewhat diagrammatised, with a few schematic figures; most are coloured, not naturally but after the fashion of a diagram, for greater clarity. There is no descriptive text, but the pictures are fully labelled. (In Head \& Neck Plate 57a the right vagus is wrongly labelled "L".) The limbs are not included.

As would be expected from a teacher of Dr. Jamieson's experience, clarity and anatomical accuracy are prominent features of the work, and commendable restraint is shown in not attempting to include too much in one illustration. But it is a pity that the stomach and intestines are represented too much as in the formalin-fixed cadaver; also, that lymph glands are ignored.

The atlas will be of undoubted value to a student in revising his work and in consolidating what he learns from actual dissections. With the aid of an epidiascope, teachers will find the removeable plates very useful for class purposes. But a surgeon who wants to refresh his memory before say, performing cervical or lumbar ganglionectomy, will find the illustrations too diagrammatic for his purpose.

Artist and printer are to be congratulated on the technical excellence of the plates, and the publishers on the really low cost of this wealth of illustration. 